\title{
Probiotics in prevention and treatment of cardiovascular diseases
}

\author{
FILIP PRZERWA ${ }^{1 \oplus}$, ARNOLD KUKOWKA $^{1 \oplus}$, KATARZYNA KOTRYCH $^{2 \oplus}$, IZABELA UZAR $^{3 *}$
}

\author{
${ }^{1}$ Student Science Club \\ Department of General Pharmacology and Pharmacoeconomics \\ Pomeranian Medical University in Szczecin \\ Szczecin, Poland \\ ${ }^{2}$ Department of General and Dental Radiology \\ Pomeranian Medical University in Szczecin \\ Szczecin, Poland \\ ${ }^{3}$ Department of General Pharmacology and Pharmacoeconomics \\ Pomeranian Medical University in Szczecin \\ Szczecin, Poland \\ *corresponding author: e-mail: uzari@wp.pl
}

\section{Summary}

Increasing knowledge of the gut microbiota and its interference in human homeostasis in recent years has contributed to a better understanding of number of different interactions occurring in the gastrointestinal tract. Disruption of the microbiota is detrimental to health and contributes to the development of numerous diseases and may also be an accelerator of pathophysiological processes such as atherosclerosis. Cardiovascular diseases are the most common cause of death worldwide, so the development of new methods to support the treatment and prevention of these diseases becoms one of the priorities of modern medicine. Probiotics may constitute an important element of support in the treatment and prevention of CVD (cardiovascular diseases). A number of papers support such a statement, however, larger clinical trials are needed. Through a number of mechanisms including mitigating inflammation, sealing the intestinal epithelium, and affecting metabolism, probiotics may have a beneficial effect on general health and slow down the pathogenesis of many diseases, including those affecting the cardiovascular system. This article contains a review of current discoveries on the role of probiotics in the prevention and support of CVD treatment.

Key words: probiotics, gastrointestinal diseases, microbiota

Słowa kluczowe: probiotyki, choroby przewodu pokarmowego, mikrobiota 


\section{INTRODUCTION}

The idea of using probiotics to support human health appeared as early as 1974, since then more and more research has been conducted on their beneficial effects on the human body. In parallel with the growing awareness of the enormous role of human microbiome, there is a growing awareness about beneficial role of probiotics in the course of many diseases [1].

Probiotics, as defined in 2001, are "live microorganisms that, when used in adequate amounts, benefit the health of the recipient" [2]. It was also proven that the gut microbiota plays an important role in maintaining the homoeostasis of the body [3]. Use of them is crucial in the support of treatment and prevention of numerous gastroenterological diseases [4]. Nevertheless, there is a sample evidence suggesting great importance of probiotics in CVD - for example, enterolactone produced by bacteria in the gut is associated with lower mortality [5]. Another evidence of the importance of the gut microbiota is that patients with a history of myocardial infarction had a different gut microbiota composition from healthy patients [6]. Some of the metabolites of the gut microbiota are trimethylamine oxide (TMAO) and short chain fatty acids (SCFA) [7]. Dietary intake of compounds such as choline, carnitine or phosphatidylcholine are converted by intestinal bacteria to trimethylamine oxide (TMA) - this is later converted to trimethylamine oxide (TMAO) in the liver and then excreted in urine $[8,9]$. TMAO is a predictor of numerous cardiovascular conditions - the higher the level is, the worse it is for the organism [10]. In particular, it plays a role in atherogenesis [7]. Abnormal intestinal microbiota contributes to the formation of larger amounts of TMAO - hence its appropriate qualitative and quantitative composition should be maintained. Probiotics may be a solution to such a problem [11]. On the other hand, short-chain fatty acids (SCFAs), which are the products of fibre metabolism, also have a positive effect on health by accelerating cholesterol metabolism $[12,13]$. The effect of probiotics in the context of cardiovascular disease requires further and expanded research which will facilitate the understanding of the interference of the microbiome in the pathogenesis of these diseases [14]. This paper presents known information on the benefits of probiotic intake in cardiovascular diseases as well as the effects of probiotics on the most relevant modifiable risk factors in the development of CVD.

\section{The most important modifiable risk factors of cardiovascular diseases}

Cardiovascular diseases such as atherosclerosis, hypertension, heart failure are the leading cause of death of patients worldwide [15]. Their risk factors are well known - obesity, smoking, hypercholesterolaemia, and diabetes [16]. More and more studies show the positive effect of probiotics on the abovementioned risk factors which may also indicate their potential in the prevention of these diseases.

\section{Hypercholesterolaemia}

Recent studies indicate that hypercholesterolaemia occurs in $70.3 \%$ of men and $64.3 \%$ of women in Poland [17]. High cholesterol level is one of the most important risk factors for atherosclerosis and plays a key role in the pathomechanism of many cardiovascular diseases. Hence, maintaining normal lipid metabolism including TC (total cholesterol), TG (triglycerides), HDL-C, LDL-C is one of the most important goals in CVD prevention [18]. A $1 \%$ reduction in serum cholesterol levels results in a $2-3 \%$ reduction in CVD incidence, so it is important to develop the tactics that can lead to decrease in cholesterol levels [19]. Probiotics can lower TC and LDL-C levels. However, they have no clear effect on serum TG and HDL-C levels. Data presented in a 2018 metaanalysis showed that the lowering effect was greater among patients with mild hypercholesterolaemia, compared to patients with moderate hypercholesterolaemia. Significant reductions in TC levels were observed with Lactobacillus plantarum, L. reuteri, L. acidophilus, while reductions in LDL-C levels were most pronounced with $L$. plantarum and a mixture of Enterococcus faecium and L. helveticus. Probiotics were administered in the form of fermented milk or in the form of probiotic capsules, however, there were no significant changes in results between these two forms [20]. There are several different proven mechanisms of fat lowering by probiotics. One of these is to bind cholesterol on their surface and incorporate it into the cell membrane, thus lowering the amount of cholesterol available for intestinal absorption [21]. Several strains of Lactobacillus can produce cholesterol reductase, which catalyses the conversion of cholesterol to coprostanol [22]. Lactobacillus bacteria can also produce ferulic acid, which can inhibit enzymes such as HMG-CoA which is involved in cholesterol synthesis $[23,24]$. Another mechanism of lowering serum cholesterol levels is the production of bile salt hydrolase, which hydrolyses bile acids and leads to 
their faster elimination in the faeces $[25,26]$. Probiotic supplementation also leads to increased levels of short-chain fatty acids, which reduces cholesterol synthesis and accelerates cholesterol metabolism [27]. Protocatechuic acid produced by bacteria in the gut promotes reverse cholesterol transport [28].

\section{Obesity}

Obesity is a multifactorial, inherited and chronic disease in which an excessive accumulation of lipids in the patient's adipose tissue occurs. The diagnosis of obesity depends on the body mass index (BMI). Obesity is defined as BMI equal to or greater than $30 \mathrm{~kg} / \mathrm{m}^{2}$. Genetic susceptibility, epigenetics, metagenomics, and environmental factors are involved in its pathomechanism. Obesity affects many aspects of health: it negatively impacts physical, mental and social health [29-31]. Recently, it is said to exist an obesity epidemic. It affects over 2 billion people. Since 1975, the number of people suffering from obesity has almost tripled. The prevalence of obesity continues to rise $[32,33]$. It has been proposed that altering the gut microbiota through oral administration of probiotics can induce weight loss and reduce weight gain, however, this mechanism is not fully understood [34]. In contrast, other studies have shown that probiotics can promote both weight gain and weight loss $[35,36]$. In a 2020 meta-analysis of studies on the role of synbiotics (a combination of a probiotic and a prebiotic) in the treatment of obesity it was found that that: synbiotics can increase weight loss, change BMI, and can improve fat mass reduction [37]. Obesity is a very important risk factor for the development of dyslipidaemia, insulin resistance, hypertension and is an accelerator of atherosclerosis. Summarising, obesity contributes to more rapid development of cardiovascular disease both in adults and children [38, 39]. The increase in the risk of the abovementioned diseases is based on the fact that obesity is a chronic inflammatory state in which an increase in the amount of adipose tissue and decrease in synthesis of adiponectin, which has an anti-inflammatory effect, play a role. This leads to a loss of balance between inflammatory and anti-inflammatory factors and thus to the development of complex metabolic complications of obesity, including endothelial dysfunction and increased insulin resistance [40].

\section{Diabetes}

According to the International Diabetes Federation (IDF), 463 million people will be diabetics in 2019 .
Diabetes is a chronic disease caused by inefficient use of insulin produced or insufficient production of insulin. Insufficient insulin levels and insulin resistance lead to hyperglycaemia. High glucose levels can lead to many complications such as diabetic kidney disease and comorbidities such as cardiovascular disease [41]. Through increased insulin resistance and metabolic changes in the body, diabetes significantly accelerates the processes of atherogenesis, thus better control of this disease will contribute to slowing down the process of atherosclerosis development and thus delay the development of heart failure. In addition, endothelial dysfunction occurs in diabetes as a result of oxidative stress resulting from higher glycaemic levels. Not only do glycaemic levels fluctuate in diabetes, but this entity also contributes to excessive platelet activity as well as myocardial fibrosis. These processes result in the development of heart failure, lead to myocardial infarctions and diabetic cardiomyopathy [42]. Probiotics may have beneficial effects on hyperglycaemia, insulin resistance, and oxidative stress. The 2020 meta-analysis showed that probiotic supplementation can improve glucose metabolism and affect body weight [43]. However, the mechanism of the beneficial effect of probiotics on hyperglycaemia is not fully understood. One hypothesis is that probiotics improve glucose levels in diabetic patients by inhibiting oxidative stress [44]. They may also increase gastrointestinal absorption of antioxidants [45]. Yao et al. showed that administration with probiotics could improve the clinical prognosis of type 2 diabetes. They significantly lowered glucose levels and alleviated insulin resistance. Lipid profile and oxidative and antioxidant stress biomarkers were also moderately improved [44]. On the other hand, Bifidobacterium bifidum with L. acidophilus and fructooligosaccharides in the form of a synbiotic cocktail reduced fasting blood glucose in elderly subjects with type 2 diabetes [46]. It is worth noting that insulin resistance is a risk factor for cardiovascular morbidity, hence, increasing insulin sensitivity can be considerd as a therapeutic target [47]. Specially prepared bread containing $L$. sporogenes and inulin may reduce serum insulin levels in diabetic patients [48]. Insulin sensitivity index can also be increased by oral administration of probiotics [49].

\section{Cardiovascular disease and probiotics}

\section{Atherosclerosis}

Atherosclerosis is a global health problem. Its pathomechanism is complex. The most important factors 
affecting its development are vascular inflammation, oxidative stress and elevated cholesterol levels [50]. The combination of these factors leads to thickening of the intima, accumulation of foam cells and formation of atherosclerotic plaque, which may enlarge and lead to vessel obstruction resulting in e.g., stroke or myocardial infarction [51]. Of the aforementioned, endothelial damage caused by oxidative stress is the most important risk factor [52]. Probiotics can enhance antioxidant mechanisms they perform this by increasing glutathione peroxidase levels, thus lowering oxidative stress [53]. The immune system also plays a key role in atherosclerotic plaque formation by inducing inflammation. Studies have shown that certain strains of probiotics, by acting as an immunomodulatory agent, can potentially reduce the number of pro-inflammatory immune cells and cytokines responsible for the inflammatory response [54].

\section{Hypertension}

About 972 million people suffer from hypertension. As a risk factor, hypertension is associated with many diseases such as chronic kidney disease, stroke and cardiovascular disease [55]. Hypertension, like atherosclerosis, has a multifactorial pathomechanism. It has been demonstrated that the gut microbiota can influence hypertension through multiple mechanisms: affecting inflammatory factors, the brain-gutkidney axis [56], or affecting TMAO levels [57], and through other metabolites produced by the gut microbiota [58]. A meta-analysis by Chi et al. presented data supporting the blood pressure lowering effect of probiotics, especially in diabetic subjects [59]. Another study also demonstrated positive effects on hypertension through different mechanisms [60]. Probiotics hydrolyse casein and lactoprotein, producing peptides that inhibit angiotensin-converting enzyme, which lower blood pressure [61]. Furthermore, animal studies have shown that probiotics have positive effects on heart muscle cells - reducing their apoptosis. They may also attenuate ventricular remodelling in spontaneously hypertensive rats [62].

\section{Heart failure}

Heart failure (HF) is a consequence of many cardiovascular diseases. It is a progressive and chronic disease caused by remodelling of the heart structure and loss of adequate cardiac function [63]. The gut microbiota is altered in patients with chronic heart failure - they have been reported to have decreased amount Faecalibacterium prausnitzii and increased amount Ruminococcus gnavus [64]. Imbalances in the gut microbiome and impaired intestinal barrier function can lead to cardiac dysfunction. First, patients with heart failure show a significant reduction in bacteria that produce short-chain fatty acids (SCFAs) [65]. E. rectale and F. prausnitzii produce butyrate [66]. Butyrate regulates epithelial barrier integrity, provides an energy source for intestinal epithelial cells, and suppresses intestinal and extraintestinal inflammation [67-69]. Second, production of harmful metabolites such as lipopolysaccharide and TMAO is higher in patients with chronic heart failure [64]. The increase in TMAO, which is a metabolite derived from the gut microbiota, is particularly significant. Patients with heart failure have higher plasma levels of TMAO, and its levels are also associated with higher mortality [70]. This lipopolysaccharide may increase inflammation and thus promote the development of heart failure [71]. Endotoxemia results from dysbiosis and leads to systemic inflammation that may contribute to the progression of heart failure [72]. The use of probiotics may decrease intestinal permeability and thus reduce systemic inflammation [73]. It has been shown that probiotics can influence the cardiac remodelling process [74]. Probiotic therapy with Lactobacillus plantarum $299 \mathrm{v}$ improved ventricular function and cardiac remodelling after left anterior descending artery ligation and reduced blood leptin levels [75]. Another study showed that the use of Saccharomyces boulardii can improve left atrial diameter and left ventricular ejection fraction in patients with $\mathrm{CHF}$ [76]. Probiotics have great potential to improve the quality of life of patients with heart failure. However, there is a great need for more clinical trials to clarify the use of probiotics in patients with heart failure.

\section{Myocardial infarction}

Animal studies by Lam et al. have shown that the use of probiotics can reduce the area of myocardial infarction [75]. Lactobacillus planatrum 299v can reduce leptin production - leading to greater resistance to cardiac ischaemia [77]. An animal study report by Gan et al. showed that probiotics can affect heart failure after myocardial infarction by reducing myocardial hypertrophy. Supplementation delayed the progression of heart failure after coronary occlusion. In addition, probiotic therapy can modulate the leptin: adiponectin ratio and reduce amino acids, nucleosides and sugar in tissues - which are factors 
produced by coronary artery occlusion in rats [74]. Nonetheless, it is still unknown if probiotics might help patients after myocardial infarction and thus clinical studies would shed more light on this topic.

\section{CONCLUSIONS}

In last few decades there has been a tremendous development in the knowledge concerning the human microbiome. Bacteria turn out to be a very important element in maintaining homeostasis of the human body. Probiotics aiming to improve - both quantitatively and qualitatively - the composition of the intestinal microbiota are also in the focus of interest of the medical world. Compounds synthesized by bacteria may have a negative effect on the body, e.g., TMAO, or a positive one, e.g., SCFA. Interfering in the pathogenesis of many diseases such as diabetes, atherosclerosis, or obesity - microorganisms in our intestines can accelerate or slow down the development of many cardiovascular diseases. Existing research results put the effect of probiotics in a positive light, but the amount of data currently available does not allow definite conclusions. Further research is necessary to develop more effective methods of prevention and treatment of cardiovascular disease using probiotics.

Ethical approval: The conducted research is not related to either human or animal use.

\section{Conflict of interest: Authors declare no conflict of} interest.

\section{REFERENCES}

1. Suez J, Zmora N, Segal E, Elinav E. The pros, cons, and many unknowns of probiotics. Nat Med 2019; 25(5):716-729. doi: https://dx.doi. org/10.1038/s41591-019-0439-x

2. Food and Agriculture Organization and World Health Organization Expert Consultation. Evaluation of health and nutritional properties of powder milk and live lactic acid bacteria. Córdoba, Argentina: Food and Agriculture Organization of the United Nations and World Health Organization; 2001. Available from: http://www.fao.org/3/ a0512e/a0512e.pdf

3. Jandhyala SM, Talukdar R, Subramanyam C, Vuyyuru H, Sasikala $M$ et al. Role of the nor- mal gut microbiota. World J Gastroenterol 2015; 21(29):8787-8803. doi: https://dx.doi. org/10.3748/wjg.v21.i29.8787

4. Przerwa F, Kukowka A, Kotrych K, Uzar I. Probiotics in the treatment of gastrointestinal diseases. Herba Pol 2021; 67(2):39-48. doi: https://dx.doi. org/10.2478/hepo-2021-0012

5. Vanharanta M, Voutilainen S, Rissanen TH, Adlercreutz H, Salonen JT. Risk of cardiovascular disease-related and all-cause death according to serum concentrations of enterolactone: Kuopio ischaemic heart disease risk factor study. Arch Intern Med 2003; 163(9):1099-1104. doi: https:// dx.doi.org/10.1001/archinte.163.9.1099

6. Kummen M, Mayerhofer C, Vestad B, Broch K, Awoyemi A, Storm-Larsen C et al. Gut microbiota signature in heart failure defined from profiling of 2 independent cohorts. J Am Coll Cardiol 2018; 71(10):1184-1186. doi: https://dx.doi. org/10.1016/j.jacc.2017.12.057

7. Peng J, Xiao X, Hu M, Zhang X. Interaction between gut microbiome and cardiovascular disease. Life Sci 2018; 214:153-157. doi: https:// dx.doi.org/10.1016/j.lfs.2018.10.063

8. Wang, Z, Klipfell E, Bennett BJ, Koeth R, Levison BS, Dugar B et al. Gut flora metabolism of phosphatidylcholine promotes cardiovascular disease. Nature 2011; 472(7341):57-63. doi: https:// dx.doi.org/10.1038/nature09922

9. Tang WH, Hazen SL. The contributory role of gut microbiota in cardiovascular disease. J Clin Investig 2014; 124(10):4204-4211. doi: https:// dx.doi.org/10.1172/JCI72331

10. Tang WH, Wang Z, Levison BS, Koeth RA, Britt $\mathrm{EB}, \mathrm{Fu} \mathrm{X}$ et al. Intestinal microbial metabolism of phosphatidylcholine and cardiovascular risk. The New England Journal of Medicine 2013; 368(17):1575-1584. doi: https://dx.doi. org/10.1056/NEJMoa1109400

11. Din AU, Hassan A, Zhu Y, Yin T, Gregersen H, Wang G. Amelioration of TMAO through probiotics and its potential role in atherosclerosis. Appl Microbiol Biotechnol 2019; 103(23-24):92179228. doi: https://dx.doi.org/10.1007/s00253019-10142-4

12. Scheppach W. Effects of short chain fatty acids on gut morphology and function. Gut 1994; 35 (1 
Suppl):S35-S38. doi: https://dx.doi.org/10.1136/ gut.35.1_suppl.s35

13. Dewulf EM, Cani PD, Claus SP, Fuentes S, Puylaert PG et al. Insight into the prebiotic concept: lessons from an exploratory, double blind intervention study with inulin-type fructans in obese women. Gut 2013; 62(8):1112-1121. doi: https:// dx.doi.org/10.1136/gutjnl-2012-303304

14. Peng J, Xiao X, Hu M, Zhang X. Interaction between gut microbiome and cardiovascular disease. Life Sci 2018; 214:153-157. doi: https:// dx.doi.org/10.1016/j.lfs.2018.10.063

15. World Health Organization. (2021, June 11). "Cardiovascular diseases (CVDs)" https://www. who.int/en/news-room/fact-sheets/detail/cardiovascular-diseases-(cvds)

16. Francula-Zaninovic S, Nola IA. Management of measurable variable cardiovascular disease' risk factors. Curr Cardiol Rev 2018; 14(3):153163. doi: https://dx.doi.org/10.2174/157340 3X14666180222102312

17. Pająk A, Szafraniec K, Polak M, Polakowska M, Kozela M, Piotrowski W et al. Changes in the prevalence, treatment, and control of hypercholesterolemia and other dyslipidemias over 10 years in Poland: the WOBASZ study. Polskie Arch Med Wewnętrznej 2016; 126(9):642-652. doi: https://dx.doi.org/10.20452/pamw.3464

18. Lu H, Daugherty A. Atherosclerosis. Arterioscler Thromb Vasc Biol 2015; 35(3):485-491. doi: https://dx.doi.org/10.1161/ATVBAHA.115.305380

19. Keil U. Coronary artery disease: the role of lipids, hypertension and smoking. Basic Res Cardiol 2000; 95 (Suppl 1):152-158. doi: https://dx.doi. org/10.1007/s003950070010

20. Mo R, Zhang X, Yang Y. Effect of probiotics on lipid profiles in hypercholesterolaemic adults: A meta-analysis of randomized controlled trials. Med Clin (Barc) 2019; 152(12):473-48. doi: https://dx.doi.org/10.1016/j.medcli.2018.09.007

21. Kimoto H, Ohmomo S, Okamoto T. Cholesterol removal from media by lactococci. J Dairy Sci 2002; 85(12):3182-3188. doi: https://dx.doi. org/10.3168/jds.S0022-0302(02)74406-8
22. Lye HS, Rusul G, Liong MT. Removal of cholesterol by lactobacilli via incorporation and conversion to coprostanol. J Dairy Sci 2010; 93(4):1383-1392. doi: https://dx.doi.org/10.3168/jds.2009-2574

23. Westfall S, Lomis N, Prakash S. Ferulic acid produced by Lactobacillus fermentum influences developmental growth through a dTOR-mediated mechanism. Mol Biotechnol 2019; 61(1):1-11. doi: https://dx.doi.org/10.1007/s12033-018-0119-y

24. Bhaskaragoud G, Rajath S, Mahendra VP, Kumar GS, Gopala Krishna AG, Kumar GS. Hypolipidemic mechanism of oryzanol components- ferulic acid and phytosterols. Biochem Biophys Res Commun 2016; 476(2):82-89. doi: https://dx.doi. org/10.1016/j.bbrc.2016.05.053

25. Klaver FA, van der Meer R. The assumed assimilation of cholesterol by Lactobacilli and Bifidobacterium bifidum is due to their bile salt-deconjugating activity. Appl Environ Microbiol 1993; 59(4):1120-1124. doi: https://dx.doi.org/10.1128/ aem.59.4.1120-1124.1993

26. Xie N, Cui Y, Yin YN, Zhao X, Yang JW, Wang ZG et al. Effects of two Lactobacillus strains on lipid metabolism and intestinal microflora in rats fed a high-cholesterol diet. BMC Complement Altern Med 2011; 11:53. doi: https://dx.doi. org/10.1186/1472-6882-11-53

27. Kumar M, Nagpal R, Kumar R, Hemalatha R, Verma V, Kumar A et al. Cholesterol-lowering probiotics as potential biotherapeutics for metabolic diseases. J Diabetes Res 2012; 2012:902917. doi: https://dx.doi.org/10.1155/2012/902917

28. Wang D, Xia M, Yan X, Li D, Wang L, Xu Y, Jin T, Ling W. Gut microbiota metabolism of anthocyanin promotes reverse cholesterol transport in mice via repressing miRNA-10b. Circ Res 2012; 111(8):967-981. doi: https://dx.doi.org/10.1161/ CIRCRESAHA.112.266502

29. Pigeyre M, Yazdi FT, Kaur Y, Meyre D. Recent progress in genetics, epigenetics and metagenomics unveils the pathophysiology of human obesity. Clin Sci (Lond) 2016; 130(12):943-986. doi: https://dx.doi.org/10.1042/CS20160136

30. Clinical guidelines on the identification, evaluation, and treatment of overweight and obesity in adults the evidence report. National Institutes 
of Health. Obes Res 1998; 6(Suppl 2):51S-209S. doi: https://dx.doi.org/10.1002/j.1550-8528.1998. tb00690.x

31. Djalalinia S, Qorbani M, Peykari N, Kelishadi R. Health impacts of obesity. Pak J Med Sci 2015; 31(1):239-242. doi: https://dx.doi.org/10.12669/ pjms.311.7033

32. Caballero B. Humans against obesity: Who will win? Adv Nutr 2019; 10 (suppl. 1):S4-S9. doi: https://dx.doi.org/10.1093/advances/nmy055

33. World Health Organization. (2021, June 9). "Obesity and overweight" https://www.who.int/newsroom/fact-sheets/detail/obesity-and-overweight

34. Sanders ME. Probiotics and microbiota composition. BMC Med 2016; 14(1):82. doi: https:// dx.doi.org/10.1186/s12916-016-0629-z

35. Drissi F, Raoult D, Merhej V. Metabolic role of lactobacilli in weight modification in humans and animals. Microb Pathog 2017; 106:182-194. doi: https://dx.doi.org/10.1016/j.micpath.2016.03.006

36. Zhang Q, Wu Y, Fei X. Effect of probiotics on body weight and body-mass index: a systematic review and meta-analysis of randomized, controlled trials. Int J Food Sci Nutr 2015; 67(5):571-580. doi: https://dx.doi.org/10.1080/09637486.2016.11811 56

37. Hadi A, Alizadeh K, Hajianfar H, Mohammadi $\mathrm{H}$, Miraghajani M. Efficacy of synbiotic supplementation in obesity treatment: A systematic review and meta-analysis of clinical trials. Crit Rev Food 2020; 60(4):584-596. doi: https://dx.doi.org /10.1080/10408398.2018.1545218

38. Barroso TA, Marins LB, Alves R, Gonçalves ACS, Barroso SG, Rocha GS. Association of central obesity with the incidence of cardiovascular diseases and risk factors. Int J Cardiovasc Sci 2017; 30(5):416-424. doi: https://dx.doi. org/10.5935/2359-4802.20170073

39. Akil L, Ahmad HA. Relationships between obesity and cardiovascular diseases in four southern states and Colorado. J Health Care Poor Underserved 2011; 22(4 Suppl):61-72. doi: https:// dx.doi.org/10.1353/hpu.2011.0166

40. Cercato C, Fonseca FA. Cardiovascular risk and obesity. Diabetol Metab Syndr 2019; 11:74. doi: https://dx.doi.org/10.1186/s13098-019-0468-0
41. International Diabetes Federation. IDF diabetes atlas, 9th edn. Brussels, Belgium: 2019. Available at: https://www.diabetesatlas.org

42. Haas AV, McDonnell ME. Pathogenesis of cardiovascular disease in diabetes. Endocrinol Metab Clin North Am 2018; 47(1):51-63. doi: https:// dx.doi.org/10.1016/j.ecl.2017.10.010

43. Jafarabadi MA, Dehghani A, Khalili L, Barzegar A, Mesrizad M, Hassanalilou TA. Meta-analysis of randomized controlled trials of the effect of probiotic food or supplement on glycemic response and body mass index in patients with type 2 diabetes, updating the evidence. Curr Diabetes Rev 2021; 17(3):356-364. doi: https:// dx.doi.org/10.2174/157333998166662008121510 29

44. Yao K, Zeng L, He Q, Wang W, Lei J, Zou X. Effect of probiotics on glucose and lipid metabolism in type 2 diabetes mellitus: A meta-analysis of 12 randomized controlled trials. Med Sci Monit 2017; 23:3044-3053. doi: https://dx.doi. org $/ 10.12659 / \mathrm{msm} .902600$

45. Fabian E, Elmadfa I. The effect of daily consumption of probiotic and conventional yoghurt on oxidant and antioxidant parameters in plasma of young healthy women. Int J Vitam Nutr Res 2007; 77(2):79-88. doi: https://dx.doi. org/10.1024/0300-9831.77.2.79

46. Moroti C, Souza Magri LF, de Rezende Costa M, Cavallini DC, Sivieri K. Effect of the consumption of a new symbiotic shake on glycemia and cholesterol levels in elderly people with type 2 diabetes mellitus. Lipids Health Dis 2012; 11:29. doi: https://dx.doi.org/10.1186/1476-511X-11-29

47. Ormazabal V, Nair S, Elfeky O, Aguayo C, Salomon C, Zuñiga FA. Association between insulin resistance and the development of cardiovascular disease. Cardiovasc Diabetol 2018; 17(1):122. doi: https://dx.doi.org/10.1186/s12933-018-0762-4

48. Tajadadi-Ebrahimi M, Bahmani F, Shakeri H, Hadaegh $\mathrm{H}$, Hijijafari M, Abedi $\mathrm{F}$ et al. Effects of daily consumption of synbiotic bread on insulin metabolism and serum high-sensitivity Creactive protein among diabetic patients: a double-blind, randomized, controlled clinical trial. Ann Nutr Metab 2014; 65(1):34-41. doi: https:// dx.doi.org/10.1159/000365153 
49. Tripolt NJ, Leber B, Blattl D, Eder M, Wonisch W, Scharnagl H, Stojakovic T et al. Short communication: Effect of supplementation with Lactobacillus casei shirota on insulin sensitivity, $\beta$-cell function, and markers of endothelial function and inflammation in subjects with metabolic syndrome a pilot study. J Dairy Sci 2013; 96(1):89-95. doi: https://dx.doi.org/10.3168/jds.2012-5863

50. Libby P, Buring JE, Badimon L, Hansson GK, Deanfield J, Bittencourt MS, Tokgözoğlu L et al. Nat Rev Dis Primers 2019; 5(1):56. doi: https:// dx.doi.org/10.1038/s41572-019-0106-Z

51. Maguire EM, Pearce S, Xiao Q. Foam cell formation: A new target for fighting atherosclerosis and cardiovascular disease. Vascul Pharmacol 2019; 112:54-71. doi: https://dx.doi.org/10.1016/j. vph.2018.08.002

52. Incalza MA, D’Oria R, Natalicchio A, Perrini $S$, Laviola L, Giorgino F. Oxidative stress and reactive oxygen species in endothelial dysfunction associated with cardiovascular and metabolic diseases. Vascul Pharmacol 2018; 100:1-19. doi: https://dx.doi.org/10.1016/j.vph.2017.05.005

53. Gomes AC, de Sousa RG, Botelho PB, Gomes TL, Prada PO, Mota JF. The additional effects of a probiotic mix on abdominal adiposity and antioxidant status: A double-blind, randomized trial. Obesity (Silver Spring) 2017; 25(1):30-38. doi: https://dx.doi.org/10.1002/oby.21671

54. Ding YH, Qian LY, Pang J, Lin JY, Xu Q, Wang LH et al. The regulation of immune cells by Lactobacilli: a potential therapeutic target for anti-atherosclerosis therapy. Oncotarget 2017; 8(35):5991559928. doi: https://dx.doi.org/10.18632/oncotarget.18346

55. Timmis A, Townsend N, Gale CP, Torbica A, Lettino M, Petersen SE et al. European Society of Cardiology: Cardiovascular disease statistics 2019. Eur Heart J 2020; 41(1):12-85. doi: https:// dx.doi.org/10.1093/eurheartj/ehz859

56. Yang T, Richards EM, Pepine CJ, Raizada MK. The gut microbiota and the brain-gut-kidney axis in hypertension and chronic kidney disease. Nat Rev Nephrol 2018; 14(7):442-456. doi: https:// dx.doi.org/10.1038/s41581-018-0018-2

57. Huart J, Leenders J, Taminiau B, Descy J, SaintRemy A, Daube G et al. Gut microbiota and fe- cal levels of short-chain fatty acids differ upon 24-hour blood pressure levels in men. Hypertension 2019; 74(4):1005-1013. doi: https://dx.doi. org/10.1161/HYPERTENSIONAHA.118.12588

58. Bartley A, Yang T, Arocha R et al. Increased abundance of lactobacillales in the colon of beta-adrenergic receptor knock out mouse is associated with increased gut bacterial production of short chain fatty acids and reduced IL17 expression in circulating CD4+ immune cells. Front Physiol 2018; 9:1593. doi: https://dx.doi.org/10.3389/ fphys.2018.01593

59. Chi C, Li C, Wu D, Buys N, Wang W, Fan H, Sun J. Effects of probiotics on patients with hypertension: a systematic review and meta-analysis. Curr Hypertens Rep 2020; 22(5):34. doi: https://dx.doi. org/10.1007/s11906-020-01042-4

60. Khalesi S, Sun J, Buys N, Jayasinghe R. Effect of probiotics on blood pressure: a systematic review and meta-analysis of randomized, controlled trials. Hypertension (Dallas, Tex. : 1979), 2014; 64(4):897-903. https://dx.doi.org/10.1161/HYPERTENSIONAHA.114.03469

61. Chen Y, Liu W, Xue J, Yang J, Chen X, Shao Y et al. Angiotensin-converting enzyme inhibitory activity of Lactobacillus helveticus strains from traditional fermented dairy foods and antihypertensive effect of fermented milk of strain H9. Int J Dairy Sci 2014; 97(11):6680-6692. doi: https:// dx.doi.org/10.3168/jds.2014-7962

62. Lin PP, Hsieh YM, Kuo WW, Lin YM, Yeh YL, Lin $\mathrm{CC}$ et al. Probiotic-fermented purple sweet potato yogurt activates compensatory IGF-IR/PI3K/Akt survival pathways and attenuates cardiac apoptosis in the hearts of spontaneously hypertensive rats. Int J Mol Med 2013; 32(6):1319-1328. doi: https://dx.doi.org/10.3892/ijmm.2013.1524

63. Ponikowski P, Voors AA, Anker SD, Bueno H, Cleland J et al. ESC Scientific Document Group. ESC Guidelines for the diagnosis and treatment of acute and chronic heart failure: The Task Force for the diagnosis and treatment of acute and chronic heart failure of the European Society of Cardiology (ESC) developed with the special contribution of the Heart Failure Association (HFA) of the ESC. Eur Heart J 2016; 37(27):2129-2200. doi: https://dx.doi.org/10.1093/eurheartj/ehw128 
64. Cui X, Ye L, Li J, Jin L, Wang W, Li S et al. Metagenomic and metabolomic analyses unveil dysbiosis of gut microbiota in chronic heart failure patients. Sci Rep 2018; 8(1):635. doi: https://dx.doi. org/10.1038/s41598-017-18756-2

65. Kamo T, Akazawa H, Suda W, Saga-Kamo A, Shimizu Y, Yagi $\mathrm{H}$ et al. Dysbiosis and compositional alterations with aging in the gut microbiota of patients with heart failure. PLoS One 2017;12(3):e0174099. doi: https://dx.doi. org/10.1371/journal.pone.0174099

66. Louis P, Flint HJ. Diversity, metabolism and microbial ecology of butyrate-producing bacteria from the human large intestine. FEMS Microbiol Lett 2009; 294(1):1-8. doi: https://dx.doi. org/10.1111/j.1574-6968.2009.01514.x

67. Furusawa Y, Obata Y, Fukuda S, Endo TA, Nakato $\mathrm{G}$ et al. Commensal microbe-derived butyrate induces the differentiation of colonic regulatory T cells. Nature 2013; 504(7480):446-450. doi: https://dx.doi.org/10.1038/nature12721

68. Leonel AJ, Alvarez-Leite JI. Butyrate: implications for intestinal function. Curr Opin Clin Nutr Metab Care 2012; 15(5): 474-479. doi: https:// dx.doi.org/10.1097/MCO.0b013e32835665fa

69. Lopez CA, Kingsbury DD, Velazquez EM, Bäumler AJ. Collateral damage: microbiota-derived metabolites and immune function in the antibiotic era. Cell Host Microbe 2014; 16(2):156-163. doi: https://dx.doi.org/10.1016/j.chom.2014.07.009

70. Tang WH, Wang Z, Fan Y, Levison B, Hazen JE, Donahue LM et al. Prognostic value of elevated levels of intestinal microbe-generated metabolite trimethylamine- $\mathrm{N}$-oxide in patients with heart failure: refining the gut hypothesis. J Am Coll Cardiol 2014; 64(18):1908-1914. doi: https:// dx.doi.org/10.1016/j.jacc.2014.02.617

71. Danesh J, Wheeler JG, Hirschfield GM, Eda S, Eiriksdottir G, Rumley A. C-reactive protein and other circulating markers of inflammation in the prediction of coronary heart disease. N Engl J Med 2004; 350(14):1387-1397. doi: https:// dx.doi.org/10.1056/NEJMoa032804
72. Dehghan P, Gargari BP, Jafar-Abadi MA, Aliasgharzadeh A. Inulin controls inflammation and metabolic endotoxemia in women with type 2 diabetes mellitus: a randomized-controlled clinical trial. Int J Food Sci Nutr 2014; 65(1):117-123. doi: https://dx.doi.org/10.3109/09637486.2013.8 36738

73. Escobedo G, López-Ortiz E, Torres-Castro I. Gut microbiota as a key player in triggering obesity, systemic inflammation and insulin resistance. Rev Invest Clin 2014; 66(5):450-9.

74. Gan XT, Ettinger G, Huang CX, Burton JP, Haist JV, Rajapurohitam V et al. Probiotic administration attenuates myocardial hypertrophy and heart failure after myocardial infarction in the rat. Circ Heart Fail 2014; 7(3):491-499. doi: https://dx.doi. org/10.1161/CIRCHEARTFAILURE.113.000978

75. Lam V, Su J, Koprowski S, Hsu A, Tweddell JS, Rafiee $\mathrm{P}$ et al. Intestinal microbiota determine severity of myocardial infarction in rats. FASEB J 2012; 26(4):1727-35. doi: https://dx.doi.org/10.1096/ f. $11-197921$

76. Costanza AC, Moscavitch SD, Faria Neto HC, Mesquita ET. Probiotic therapy with Saccharomyces boulardii for heart failure patients: a randomized, double-blind, placebo-controlled pilot trial. Int J Cardiol 2014; 179:348-350. doi: https:// dx.doi.org/10.1016/j.ijcard.2014.11.034

77. Purdham DM, Rajapurohitam V, Zeidan A, Huang C, Gross GJ, Karmazyn M. A neutralizing leptin receptor antibody mitigates hypertrophy and hemodynamic dysfunction in the postinfarcted rat heart. Am J Physiol Heart Circ Physiol. 2008; 295(1):H441-6. doi: https://dx.doi. org/10.1152/ajpheart.91537.2007 